\title{
Mesenchymal stem cells-derived exosomes for drug delivery
}

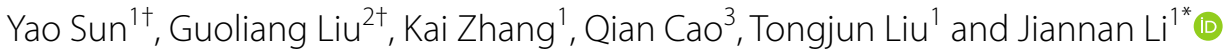

\begin{abstract}
Exosomes are extracellular vesicles secreted by various cells, mainly composed of lipid bilayers without organelles. In recent years, an increasing number of researchers have focused on the use of exosomes for drug delivery. Targeted drug delivery in the body is a promising method for treating many refractory diseases such as tumors and Alzheimer's disease (AD). Finding a suitable drug delivery carrier in the body has become a popular research today. In various drug delivery studies, the exosomes secreted by mesenchymal stem cells (MSC-EXOs) have been broadly researched due to their immune properties, tumor-homing properties, and elastic properties. While MSC-EXOs have apparent advantages, some unresolved problems also exist. This article reviews the studies on MSC-EXOs for drug delivery, summarizes the characteristics of MSC-EXOs, and introduces the primary production and purification methods and drug loading methods to provide solutions for existing problems and suggestions for future studies.
\end{abstract}

Keywords: Mesenchymal stem cells, Exosomes, Drug delivery, Targeting

\section{Introduction}

Mesenchymal stem cells (MSCs) are multi-functional stem cells that are present in multiple human tissues. They can be found in the spinal cord, umbilical cord blood, umbilical cord tissue, placenta tissue, adipose tissue, etc. $[1,2]$. With low immunogenicity, multi-directional differentiation ability, in particular homing ability, it has significant research potential in cardiovascular diseases, nervous diseases, and hematopoietic diseases [3]. The drug delivery system based on MSCs has become one of the most attractive therapeutic methods because of its characteristics. However, cells as drug carriers still face many problems such as uncertain differentiation accidents, cell embolism, infection, production, and storage [4]. As the secretion of MSCs, the exosomes inherit the relative advantages of MSCs and overcome the problems of MSCs as drug carriers [5].

\footnotetext{
*Correspondence: jnli@ciac.ac.cn

${ }^{\dagger}$ Yao Sun and Guoliang Liu contributed equally to this work

${ }^{1}$ Department of General Surgery, The Second Hospital of Jilin University,

No. 218 Ziqiang Street, Changchun 130041, China

Full list of author information is available at the end of the article
}

The exosomes are secreted by mesenchymal stem cells (MSC-EXOs), most of which are cup-shaped or round with a diameter of 30-100 nm and a density of $1.13-1.19 \mathrm{~g} / \mathrm{ml}$ [6]. The exosomes contain lipid, protein, and RNA [7]. The lipid bilayer maintains the integrity of exosomes and stabilizes biological activities. Protein modification on the surface enhances the recognition and targeting ability of the exosomes. Abundant RNA in the capsule improves the imaginative potential to regulate the transcription and translation of receptor cells. With different sources of MSC, the characteristics of the exosomes are different [8]. MSC-EXOs have many unique characteristics, such as small size, low immunogenicity, long-circulating half-life, good penetration, and good biocompatibility. It is one of the best choices for researchers to find drug carriers in vivo [9]. In current studies, researchers use MSC-EXOs as a carrier to deliver RNA, protein, and molecular drugs to specific parts of the body to achieve targeted therapy. However, problems such as carrier separation and purification, preservation and transportation, drug loading, and targeting still exist [10]. In this study, we first summarized the production and drug loading methods of MSC-EXOs, and the

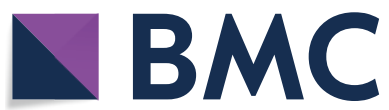

(C) The Author(s) 2021. Open Access This article is licensed under a Creative Commons Attribution 4.0 International License, which permits use, sharing, adaptation, distribution and reproduction in any medium or format, as long as you give appropriate credit to the original author(s) and the source, provide a link to the Creative Commons licence, and indicate if changes were made. The images or other third party material in this article are included in the article's Creative Commons licence, unless indicated otherwise in a credit line to the material. If material is not included in the article's Creative Commons licence and your intended use is not permitted by statutory regulation or exceeds the permitted use, you will need to obtain permission directly from the copyright holder. To view a copy of this licence, visit http://creativecommons.org/licenses/by/4.0/. The Creative Commons Public Domain Dedication waiver (http://creativecommons.org/publicdomain/zero/1.0/) applies to the data made available in this article, unless otherwise stated in a credit line to the data. 
modification of MSC-EXOs for targeted drug delivery. Secondly, the delivery of RNA, small molecular drugs, and proteins by MSC-EXOs to treat different kinds of diseases was discussed. Furthermore, we also provided our perspectives for enhancing the drug loading efficacy of MSC-EXOs.

\section{MSC-EXOs}

\section{Production of MSC-EXOs}

As a drug carrier in vivo, a safe, efficient, and reliable purification method is necessary. The researchers improved the production of MSC-EXOs by changing the composition of MSC or the culture media [11].

MSCs cannot proliferate indefinitely, which limits the production of MSC-EXOs. The researchers transfected the MYC gene into MSC to obtain immortalized MSCs to increase the production of MSC-EXOs [12]. The results showed that MSCs transfected with the MYC grew faster, had less adhesion, and did not age. The exosomes produced by MSCs transfected with the MYC had the same effect as non-transfected MSCs. It showed that the MYC transfection is a feasible method for mass production of MSC-EXOs. The immortalization of MSC produces an infinitely expandable MSC clone cell line to increase the production of MSC-EXOs. This method allows MSC-EXOs to be produced from MSC of the same source, ensuring the consistency of different batches of MSC-EXOs as much as possible. It provided the possibility for the quality control of mass production of MSCEXOs [13]. However, researchers indicated that the MYC is a proto-oncogene; it may cause unknown side effects in clinical practices [14].

Researchers have used scaffolds, spherical culture, hollow fiber bioreactor, and microcarrier-based 3D culture methods to achieve higher exosomes production [15]. Cao et al. inoculated MSCs into a hollow fiber bioreactor for 3D culture. The 3D culture increased the exosomes productions by 20 times compared with $2 \mathrm{D}$ culture. Transmission electron microscopy and western blotting were used to verify that there was no significant difference in the shape, size, surface markers of exosomes, and even better biological activity. It shows that it is feasible to use this method to increase yield [16]. Compared with the $2 \mathrm{D}$ culture system, the effective medium area of the $3 \mathrm{D}$ culture system is more extensive, and the distribution of exosomes in the supernatant is more concentrated, which improves the collection efficiency and reduces the use of consumables.

Stimulating MSC with biological materials or a specific culture media can also increase its paracrine capacity. Sung et al. made the comparison between thrombin, hypoxia, hydrogen peroxide, and lipopolysaccharide. The results showed that the four preconditions could enhance the production of exosomes. The thrombin could increase the yield of exosome by more than four times and enrich the exosome "goods" content [17]. However, these preconditions will produce unhealthy cells and excess MSC-EXOs [18]. 45S5 Bioglass ${ }^{\circledR}$ (BG) is one of the new generations of bioactive inorganic materials. The ions produced by BG can promote proliferation, differentiation, and secretion. They also provide a peaceful and friendly environment for the cells, so they will not be damaged. According to its characteristics, $\mathrm{Wu}$ et al. applied BG to the experiment of promoting MSC paracrine to produce more exosomes. The results showed that BG could stimulate MSC to produce more exosomes and enhance the biological function of exosomes by enhancing neutral sphingomyelinase-2 (nSMase2) and Rab GTPases pathways [19]. The exosomes production was increased by stimulating the MCS with the biological method. Compared with the traditional method of changing cell culture conditions, it has more advantages and lower costs.

From internal to external, from physical conditions to biomolecular regulation, researchers have proposed ways to increase the production of MSC-EXOs from various aspects. However, the methods proposed by the researchers will more or less affect the biological function of MSC-EXOs. And some of the impacts could be uncontrollable and unproven $[11,14]$. In the future, researchers may need to integrate multiple methods to form standardized and consistent quality procedures to propose methods for mass production of MSC-EXOs.

\section{Separation and purification of MSC-EXOs}

The exosome isolation and purification method will also affect the yield, purity, composition, and function of MSC-EXOs. At present, the widely used ultracentrifugation has limited scalability, fragmentation, and aggregation in terms of exosomes separation. Researchers developed new methods to optimize the separation and purification process of MSC-EXOs, including tangential flow filtration (TFF), precipitation method, and density gradient accumulation [20-25]. TFF is a method with solid expansibility and a high degree of purification. It can extract viruses and proteins from a large amount of cell culture fluid. Haraszti et al. combined TFF with 3D culture to obtain 20 times higher exosome yield than traditional methods [20]. However, TFF needs expensive equipment and is an open system with a higher risk of pollution. It still needs to be improved. Börger et al. referred to the polyethylene glycol (PEG) precipitation separation scheme of the virus. Considering the same physical characteristics of exosomes and viruses, PEG (10\% PEG 6000) was applied to isolate MSC-EXOs. Results showed that the exosome yield was 14 times 
higher than that of traditional conventional differential centrifugation protocols [24]. The difference in the weight and concentration of PEG molecular would significantly influence the yield of exosomes but cannot affect the size of isolated exosomes. Ludwig et al. compared the yield of exosomes extracted of different molecular weights and concentrations of PEG. The results showed that $10-12 \%$ PEG 6000, 8-10\% PEG 8000, and 8-10\% PEG 20,000 were appropriate for separating exosomes. However, the dissolved PEG 20,000 was not suitable for MSC-EXOs isolation because its high viscosity makes it difficult to handle [26]. Studies have shown that densities influence the contents and characteristics of MSC-EXOs, so it is necessary to separate MSC-EXOs of different densities [27]. Gorgun et al. used density gradient centrifugation to separate vesicles of different sizes from mixed exosomes. A new flow cytometry method was also applied to characterize vesicles with a diameter of fewer than $1 \mu \mathrm{m}$ [22]. Chopra et al. used ultracentrifugation (UC), sucrose cushion (SC), and total exosome isolation commercial reagent (CR) to separate Human Wharton's Jelly-Derived MSCs. The results showed that the exosomes extracted by SC have the highest purity [28].

So far, the various methods have limitations such as scalability, equipment complexity, purity control of the extracted vesicles, and pollution control. We should selectively integrate various methods and develop a complete set of separation and purification. This is a long way from large-scale therapeutical use [29].

\section{Quality control and safety}

The drugs' massive production requires the following GMP (Good Manufacture Practice of Medical Products, GMP). As the production and purification process affects the properties of MSC-EXOs, it is necessary to set a standard for MSC-EXOs to achieve consistency of quality and safety [30]. Many studies have shown that MSCEXOs transplanted into recipient organization are safe. Sun et al. conducted the intravenous injection on the rat model of myocardial infarction to evaluate the safety of transplantation hucMSC (human umbilical cord MSC). The experiment proved that the hucMSC is safe without any side effects [31]. However, this does not fulfill the quality and safety requirements in large-scale clinical applications. A report that "process is product" emphasizes quality control at every step and level. From the production of cells to purification, separation, storage, and final application, all are carried out following GMP standards [32]. Researchers should be highly aware of the administration dosage, stability, safety, toxicity, shelf life, and other biopharmaceutical characteristics.

\section{Loading methods}

Efficient loading of biological cargo into MSC-EXOs is a very critical step. Currently, researchers used different loading methods for different types of biological cargo [33]. At present, methods such as electroporation, transfection, and overexpression are commonly used. The main advantages and disadvantages of the above three methods are shown in Table 1.

Transfection is the most commonly used method to introduce RNA into exosomes. Lou et al. used plasmids to transfect miR-122 into adipose tissue-derived MSC (AMSC) successfully. The PCR method was used to check the expression level of miR-122 in exosomes [34]. There are also studies on directly transfecting RNA into exosomes, and good transfection efficiency has also been obtained. Zhang et al. reported a calcium chloride-mediated transfection method, which directly transfected the target RNA into exosomes instead of the parent cell [35]. However, studies have also pointed out that due to changes in gene expression and regulated transfection of production cells, an infection may cause potential toxicity or biosafety issues [36].

The electroporation technique uses an electric field to form temporary hydrophilic pores on the phospholipid membrane of the exosomes to load the biological cargo into the exosomes [37]. Gomari et al. used electroporation technology to load doxorubicin into the MSC-EXOs successfully. The loading efficiency was measured by a spectrophotometer [38]. However, some studies have pointed out that electroporation can cause RNA aggregation and changes in the morphology of exosomes [39]. RNA accumulation can cause the loaded RNA to lose its function, decreasing loading efficiency [40]. Hood et al. found that electroporation could increase the size of exosomes, forming aggregates. Such changes in the morphology of exosomes are not beneficial for maintaining

Table 1 The advantages and disadvantages of several commonly used loading methods

\begin{tabular}{llll}
\hline Methods & Type of cargo & Advantages & Disadvantages \\
\hline Transfection & RNA & $\begin{array}{l}\text { Good load efficiency and } \\
\text { stability of the molecule }\end{array}$ & Potential toxicity and genetic changes \\
Electroporation & Hydrophilic cargo & Wide applicability & $\begin{array}{l}\text { Require sophisticated equipment/possible molecular } \\
\text { aggregation/morphological changes of exosomes }\end{array}$ \\
Overexpression & Protein & Simple and convenient & May cause imbalance of cell proliferation and apoptosis \\
\hline
\end{tabular}


the stability of exosome function in vivo and during storage. They developed a culture system containing trehalose, successfully maintaining the original size of exosomes and reducing the aggregation of exosomes [41].

Overexpression is often used for the loading of protein cargo. Transfection inserts gene fragments to regulate cell protein synthesis. The target protein will be loaded into the exosome through separation and purification. This method is technically mature and easy to operate. Huang et al. successfully loaded pigment epitheliumderived factor (PEDF) into ADSC-derived exosomes by overexpression and identified the expression of PEDF in exosomes by western blotting [42]. However, the report also pointed out that the overexpression of a specific protein may cause an imbalance of cell proliferation and apoptosis. This imbalance will reduce the proliferation rate of MSCs, inhibiting the production of exosomes. Exosomes may also be loaded with unwanted proteins with unpredictable effects on therapy. Therefore, more advanced sorting systems need to be developed to overcome the loading and expression of non-specific proteins $[33,43]$.

There are also other loading methods, such as incubation, ultrasonic treatment, and extrusion. However, there is a lack of horizontal comparison of different loading methods in the current research. For the clinical application of MSC-EXOs, it is necessary to find an optimal loading method.

\section{Targeting}

In many diseases, targeted therapies are promising methods that reduce the adverse impact on other areas while improving the therapeutic effect of drugs on the target area. The researchers conducted a lot of studies on how to improve the targeting of MSC-EXOs.

\section{Targeting peptide}

Peptides conjugated on the surface of MSC-EXOs can improve the targeting of MSC-EXOs [44]. Using targeting peptides has been applied to research breast cancer, lung cancer, liver cancer, heart disease, and brain disease.

In order to achieve the targeting delivery of drugs to the acute myocardial infarction area, Wang et al. applied CTnI-targeted peptides on MSC-EXOs by gene-transfecting MSC cells. CTnI is highly expressed in the area of myocardial infarction, and the modified exosomes can be transported to this area through the concentration gradient of CTnI [45]. In the study of Wang et al., they applied the IMTP (ischemic myocardium-targeting peptide) motif CSTSMLKAC onto MSC-EXOs membrane to target the ischemic myocardium. The results showed that IMTP exosomes significantly improved the targeting ability [46].
Exosomes can cross the blood-brain barrier, but recent studies have shown that exosomes accumulate in the liver and spleen after systemic injection, while the signal in the brain is relatively weak. Therefore, it is necessary to improve the distribution level of exosomes in the brain [47]. Cui et al. connected central nervous system-specific rabies viral glycoprotein (RVG) peptide on MSC-EXOs to achieve greater cortex and hippocampus targeting [48]. Jia et al. bound neuropilin-1-targeted peptide (RGERPPR, RGE) to the MSC-EXOs membrane by click chemistry to achieve targeting glioma. They also loaded superparamagnetic iron oxide nanoparticles (SPIONs) and curcumin (Cur) into MSC-EXOs. Their results showed that the modified MSC-EXOs can smoothly pass to the targeting area with good imaging and treatment effects [49].

Modifying the targeting peptide on the surface of exosomes is an efficient and direct method to improve the targeting of exosomes. This method requires selecting suitable targeting peptides for different lesions and choosing a suitable method to connect the targeting peptides with exosomes [50]. The main modification methods are genetic engineering, covalent modification, and non-covalent modification [51]. Adding targeting peptides can develop specific targeting peptides for each disease, and the application scenarios are extensive. However, challenges such as unexpected immunogenicity problems and the impact of the connection process still exist. These require researchers to better understand the characteristics of the surface composition, connection methods of MSC-EXOs, and the mechanism of disease.

\section{Magnetic targeting}

Studies have shown that an external magnetic field can control the biodistribution of iron oxide nanoparticles (IOPN) in the body after intravenous injection. The FDA (Food and Drug Administration) approves IOPN to treat iron deficiency anemia. It has biocompatibility and is ionized into iron ions and iron homeostasis. Thus, this is a feasible method to improve the targeting of exosomes. Kim et al used IONP-harbored MSC to prepare the MSC-EXOs. The MSC-EXOs containing IOPN can navigate to the target area under the guidance of an external magnetic field. The results showed that the localization concentration increased by 5.1 times under in vitro magnetic navigation [52]. Kim et al. used PEGylated superparamagnetic IONP to improve the magnetization and colloidal stability in serum to prepare the IOPN-MSCEXOs. The results showed that the magnetic navigation increased the amount of MSC-EXOs accumulating in the targeting area (spinal cord injury area) and the IOPN also stimulated the increase in therapeutic factors in the MSC-EXOs [53]. Lee et al. and Altanerova et al. also obtained similar results [54]. Jia et al. combined magnetic 
targeting and targeting peptides to enhance the targeting of MSC-EXOs. They loaded curcumin (Cur) and superparamagnetic IONP (SPIONs) into the MSC-EXOs and connected a membrane-targeting peptide. The RGE-ExoSPION/Cur showed good targeting, biocompatibility, and therapeutic effects [49].

The magnetic navigation method is "non-invasive" compared to modifying the surface proteins of exosomes. It is an auspicious method with a lower impact on the exosomes.

\section{Evaluation of targeting efficacy}

As a promising drug for large-scale clinical use, it is inevitable to have precise tracking and biodistribution in vivo. Although researchers have conducted many experiments on MSC-EXOs, there is a lack of research on tracking and biodistribution in vivo [55]. At present, the primary methods for labeling MSC-EXOs in organisms are as follows: One is to wrap metal nanoparticles in exosomes, perform high-sensitivity magnetic resonance or CT analysis [52, 56], use radioactive tracers and nuclear imaging for tracking [57], and stained with fluorescent dyes [58]. Perets et al. developed a new visualization method that loaded glucose-coated GNPs (gold nanoparticles) into MSC-EXOs and used classical X-ray computed tomography $(\mathrm{CT})$ to perform imaging to evaluate the biodistribution of MSC-EXOs in different pathological types of brain. The results clearly showed that the distribution of MSC-EXOs in the brain was closely related to inflammation [59]. Betzer et al. [60] and Cohen et al. [56] also used similar methods to evaluate the biodistribution of MSCEXOs in the body. By studying the tracing of MSC-EXOs in the body, we can better research biodistribution, pharmacodynamics, targeting, etc.

The biodistribution of MSC-EXOs in the body is related to the source, size, injection method, and other factors of exosomes. MSC-EXOs accumulated more at the tumor site via local injection. They can also be quickly delivered into the liver and spleen via intravenous injection. Efficient exosomes delivery made the intranasal treatment more convenient.

\section{Delivery of different types of "drugs" in vivo Delivery of RNA by MSC-EXOs Mechanism}

RNA participates in the regulation of many cell activities. Among them, the most widely used MSC-EXOs targeted transport is miRNA. It can bind to the protein to change its function, target mitochondria to affect mitochondrial function, and activate the process of gene transcription. It can down-regulate the expression of noncoding genes and other processes to affect cell life activities. Therefore, the targeted transport of RNA is widely used in the research of various diseases [61]. By loading RNA, MSCEXOs are often applied in the treatment of tumors, brain diseases, and spinal cord injuries.

Table 2 shows the study of MSC-EXOs RNA delivery in vivo in recent years [34, 62-86].

\section{For Tumor}

Many studies have shown that the occurrence, proliferation, and metastasis of tumors are closely related to the abnormal levels of specific RNAs [69]. Researchers tried to use MSC-EXOs' targeting ability to regulate the level of specific RNA to treat tumors. Currently, RNA targeting has been expressively applied to breast cancer, hepatocellular carcinoma, and pancreatic ductal adenocarcinoma (PDAC). Breast cancer is the highest incidence of malignant tumors in women. Because of its late metastasis, it can cause multiple organ diseases, which seriously threaten the lives of patients. Studies have shown that the up-regulation of miR-142-3p and miR-150 is related to the tumorigenic breast cancer stem cells [87]. Therefore, Naseri et al. loaded LNA (locked nucleic acid)-modified anti-miR-142-3p oligonucleotides into MSC-EXOs. They used MSC-EXOs to deliver anti-miR-142-3p to breast cancer sites to enforce the expression of miR-142-3p and miR-150 in cancer cells. The results showed that, whether in vivo or in vitro, MSC-EXOs can deliver LNA-antimiR-142-3p to the target site, enforce the expression of target RNA, and improve the transcription level of target genes APC and P2X7R. The results also showed that the MSC-EXOs had good biodistribution and successfully suppressed tumor growth [88, 89]. Hepatocellular carcinoma is highly resistant to conventional chemotherapy. Studies have shown that microRNA-122 (miR-122) is closely related to the occurrence and development of hepatocellular carcinoma and chemotherapy sensitivity [90]. Therefore, Lou et al. used MSC-EXOs to deliver miR-122 to the tumor tissue to improve the sensitivity of hepatocellular carcinoma to chemotherapy. The results showed that MSC-EXOs successfully delivered miR-122 and increased the sensitivity of hepatocellular carcinoma to sorafenib. ADAM10, IGF1R, and CCNG1 may be the predicted targets of miR-122, and down-regulating their expression levels can induce cell apoptosis and cell cycle arrest, thereby improving the chemotherapy sensitivity of hepatoma [34]. Lou et al. used MSC-EXOs to deliver miR-199a to target the mTOR (an oncogene related to cancer chemotherapy sensitivity) pathway, which also successfully improved the sensitivity of hepatocellular carcinoma [66]. PDAC is one of the cancers with a very high mortality rate. The lack of effective treatments makes it an incurable disease for most patients. Ding et al. used MSC-EXOs to deliver exogenous miR145-5p. The results showed that it successfully inhibited 
Table 2 Delivery of RNA by MSC-EXOs

\begin{tabular}{|c|c|c|c|c|c|c|}
\hline RNA & Exosomes origin & Loading methods & $\begin{array}{l}\text { Administration } \\
\text { route }\end{array}$ & Model & Aim & References \\
\hline miR-122 & AMSC & Transfection & Intra-tumor injection & Mice & $\begin{array}{l}\text { Enhance HCC che- } \\
\text { mosensitivity }\end{array}$ & [34] \\
\hline miRNA-181-5p & AMSC & Transfection & Intrasplenic injection & Mice & Prevent liver fibrosis & {$[67]$} \\
\hline microRNA-584 & BMSCs & Transfection & Local injection & Mice & $\begin{array}{l}\text { Reduce glioma } \\
\text { activity }\end{array}$ & {$[62]$} \\
\hline miR-132 & BMSCs & Electroporation & Local injection & Mice & $\begin{array}{l}\text { Promote angiogen- } \\
\text { esis }\end{array}$ & [107] \\
\hline LNA-anti-miR-142-3p & BMSCs & Electroporation & Intravenous injection & Mice & $\begin{array}{l}\text { Reduce tumorigenic- } \\
\text { ity of breast cancer }\end{array}$ & {$[88]$} \\
\hline miR-379 & BMSCs & Transfection & Intravenous injection & Mice & $\begin{array}{l}\text { Reduce breast can- } \\
\text { cer activity }\end{array}$ & {$[72]$} \\
\hline miR-124 & WJMSCS & Transfection & In vitro experiment & GBM cancer cells & $\begin{array}{l}\text { Reduce glioblastoma } \\
\text { multiform cells } \\
\text { activity }\end{array}$ & {$[73]$} \\
\hline miR-133b & BMSCs & Transfection & Intravenous injection & Mice & Neuroprotective role & {$[64]$} \\
\hline miR-145-5p & HucMSCs & Transfection & Intra-tumor injection & Mice & $\begin{array}{l}\text { Inhibit pancreatic } \\
\text { ductal adenocarci- } \\
\text { noma }\end{array}$ & [91] \\
\hline miR-675 & HucMSCs & Transfection & Local injection & Mice & $\begin{array}{l}\text { Treat aging-induced } \\
\text { vascular dysfunction }\end{array}$ & [110] \\
\hline miR-126 & BMSCs & Transfection & $\begin{array}{l}\text { In vitro cell experi- } \\
\text { ment }\end{array}$ & N/A & $\begin{array}{l}\text { Ameliorate hypoxia/ } \\
\text { reoxygenation- } \\
\text { injured ECs }\end{array}$ & [108] \\
\hline miR-644-5p & BMSCs & Transfection & Intravenous injection & $\begin{array}{l}\text { Cisplatin-induced } \\
\text { POF mouse mode }\end{array}$ & $\begin{array}{l}\text { Inhibit ovarian } \\
\text { granulosa cell } \\
\text { apoptosis }\end{array}$ & [74] \\
\hline miR-34a & BMSC & Transfection & Intravenous injection & Mice & Reduce GBM activity & [93] \\
\hline miR-29b & BMSC & Transfection & Intravenous injection & Mice & $\begin{array}{l}\text { Repair spinal cord } \\
\text { injury in rats }\end{array}$ & {$[63]$} \\
\hline tsRNA-10277 & BMSC & Transfection & $\begin{array}{l}\text { In vitro cell experi- } \\
\text { ment }\end{array}$ & N/A & $\begin{array}{l}\text { Enhance osteogenic } \\
\text { differentiation ability } \\
\text { of dexamethasone- } \\
\text { induced BMSCs }\end{array}$ & {$[75]$} \\
\hline miR-126 & BMSC & Transfection & Intravenous injection & Rats & $\begin{array}{l}\text { Promote repair after } \\
\text { spinal cord injury }\end{array}$ & {$[68]$} \\
\hline MiR-29 & BMSC & Transfection & Local injection & Rats & $\begin{array}{l}\text { Potential treatments } \\
\text { for } A D\end{array}$ & {$[96]$} \\
\hline miR-499 & BMSC & Electroporation & $\begin{array}{l}\text { Intratumorally } \\
\text { injected }\end{array}$ & Mice & $\begin{array}{l}\text { Inhibit endometrial } \\
\text { cancer growth and } \\
\text { metastasis }\end{array}$ & {$[76]$} \\
\hline miR-544 & BMSCs & $\begin{array}{l}\text { Transfection (incu- } \\
\text { bate together) }\end{array}$ & Intravenous injection & Rats & $\begin{array}{l}\text { Promote repair after } \\
\text { spinal cord injury }\end{array}$ & [97] \\
\hline miR-199a & AMSCS & Transfection & Intravenous injection & Mice & $\begin{array}{l}\text { Improve HCC che- } \\
\text { mosensitivity }\end{array}$ & {$[66]$} \\
\hline miR-29a & BMSCs & Transfection & Intravenous injection & Mice & $\begin{array}{l}\text { Promote angiogene- } \\
\text { sis and osteogenesis }\end{array}$ & [112] \\
\hline LNA-antimiR-142-3p & BMSCs & Electroporation & $\begin{array}{l}\text { In vitro cell experi- } \\
\text { ment }\end{array}$ & Mice & $\begin{array}{l}\text { Reduce the tumo- } \\
\text { rigenicity of breast } \\
\text { cancer stem cells } \\
\text { in vivo }\end{array}$ & [89] \\
\hline miRNA-126-3p & HucMSCs & Transfection & $\begin{array}{l}\text { In vitro cell experi- } \\
\text { ment and intrave- } \\
\text { nous injection }\end{array}$ & Mice & $\begin{array}{l}\text { Enhance endothe- } \\
\text { lial function and } \\
\text { attenuate vein graft } \\
\text { neointimal formation }\end{array}$ & [77] \\
\hline miR-326 & HucMSC & Transfection & Intravenous injection & Mice & $\begin{array}{l}\text { Relieve DSS-induced } \\
\text { IBD }\end{array}$ & [78] \\
\hline
\end{tabular}


Table 2 (continued)

\begin{tabular}{|c|c|c|c|c|c|c|}
\hline RNA & Exosomes origin & Loading methods & $\begin{array}{l}\text { Administration } \\
\text { route }\end{array}$ & Model & Aim & References \\
\hline miR-19a/19b & BMSCs & Transfection & Intravenous injection & Mice & $\begin{array}{l}\text { Mitigate the dam- } \\
\text { age of myocardial } \\
\text { infarction }\end{array}$ & [70] \\
\hline MiR-17-92 & BMSCs & Transfection & Intravenous injection & Mice & $\begin{array}{l}\text { Enhance axon-mye- } \\
\text { lin remodeling and } \\
\text { motor electrophysi- } \\
\text { ological recovery } \\
\text { after stroke }\end{array}$ & {$[65]$} \\
\hline miR-124 & BMSCs & Transfection & $\begin{array}{l}\text { Subcutaneous injec- } \\
\text { tion }\end{array}$ & Mice & $\begin{array}{l}\text { Treatment of pancre- } \\
\text { atic tumors }\end{array}$ & [71] \\
\hline miR-124 & HADMSCS & Transfection & $\begin{array}{l}\text { In vitro cell experi- } \\
\text { ment }\end{array}$ & $\begin{array}{l}\text { M17 human NB cell } \\
\text { line }\end{array}$ & $\begin{array}{l}\text { Therapy for NB } \\
\text { cancer }\end{array}$ & [79] \\
\hline miR-214 & BMSCs & Transfection & $\begin{array}{l}\text { Intracerebroventricu- } \\
\text { lar injection }\end{array}$ & Rats & $\begin{array}{l}\text { Neuroprotection } \\
\text { against cerebral }\end{array}$ & {$[80]$} \\
\hline miR-381 & ADMSC & Electroporation & $\begin{array}{l}\text { In vitro cell experi- } \\
\text { ment }\end{array}$ & MDA-MB-231 cells & $\begin{array}{l}\text { Inhibit triple-neg- } \\
\text { ative breast cancer } \\
\text { aggressiveness }\end{array}$ & {$[81]$} \\
\hline aiR-34a & $\begin{array}{l}\text { Dental pulp MSCs } \\
\text { (DPSCs) }\end{array}$ & $\begin{array}{l}\text { Transfection } \\
\text { (Lentiviral miR-34a } \\
\text { transduction) }\end{array}$ & $\begin{array}{l}\text { In vitro cell experi- } \\
\text { ment }\end{array}$ & MDA-MB-231 cells & $\begin{array}{l}\text { Repress proliferation } \\
\text { of breast carcinoma } \\
\text { cells }\end{array}$ & {$[82]$} \\
\hline miR-135B & BMSCs & Transfection & $\begin{array}{l}\text { Articular cavity } \\
\text { injection }\end{array}$ & OA rat model & $\begin{array}{l}\text { Attenuate the } \\
\text { damage of cartilage } \\
\text { tissues }\end{array}$ & [83] \\
\hline miR-155-5P & $\begin{array}{l}\text { Synovial MSCs } \\
\text { (SMSCs) }\end{array}$ & Transfection & $\begin{array}{l}\text { Articular cavity } \\
\text { injection }\end{array}$ & OA rat model & OA therapy & {$[84]$} \\
\hline miR-126 & BMSCs & Transfection & $\begin{array}{l}\text { In vitro cell experi- } \\
\text { ment }\end{array}$ & $\begin{array}{l}\text { Human umbilical } \\
\text { vein endothelial cells }\end{array}$ & $\begin{array}{l}\text { Pro-angiogenic } \\
\text { potential }\end{array}$ & {$[85]$} \\
\hline MicroRNA-let7c & BMSCs & $\begin{array}{l}\text { Lentiviral transduc- } \\
\text { tion }\end{array}$ & $\begin{array}{l}\text { Administered intra- } \\
\text { venously }\end{array}$ & Rats & $\begin{array}{l}\text { Attenuate renal } \\
\text { fibrosis }\end{array}$ & {$[86]$} \\
\hline PTEN-siRNA & BMSCs & Incubated & Intranasal injection & Rats & $\begin{array}{l}\text { Promote recovery } \\
\text { for SCl }\end{array}$ & [98] \\
\hline miR-21 & HucMSC & Transfection & $\begin{array}{l}\text { In vitro cell experi- } \\
\text { ment }\end{array}$ & $\beta$-cells & $\begin{array}{l}\text { Treatment of dia- } \\
\text { betes }\end{array}$ & [100] \\
\hline miR-375 & BMSCs & Transfection & $\begin{array}{l}\text { In vitro cell experi- } \\
\text { ment }\end{array}$ & $\beta$-cells & $\begin{array}{l}\text { Treatment of dia- } \\
\text { betes }\end{array}$ & [101] \\
\hline miR-125a & ADMSC & Transfection & Intravenous injection & Rats & $\begin{array}{l}\text { Diabetic nephropa- } \\
\text { thy }\end{array}$ & [104] \\
\hline miR-126 & HucMSC & Transfection & Local injection & Rats & Diabetic eye diseases & {$[105]$} \\
\hline IncRNA H19 & BMSCs & Transfection & Local injection & Rats & Diabetic foot ulcer & {$[106]$} \\
\hline
\end{tabular}

N/A, not applicable

the proliferation and metastasis of cancer cells in mice. The author believed that this may be closely related to miR-145-5p targeting mRNA 3'UTR regions of Smad3 (Recombinant Human Mothers Against Decapentaplegic Homolog 3) to down-regulate its expression [91].

The treatment of cancer by MSC-EXOs can start from the following aspects. On the one hand, the close relationship between RNA and cell activities can directly inhibit the growth of cancer cells. On the other hand, RNA can be delivered to improve the sensitivity of cancer cells to radiotherapy and chemotherapy to optimize the treatment effect. The RNA changes in cancer are diverse with increase and decrease. In future research, we may treat multiple RNA changes simultaneously to get more reliable results.

\section{For brain diseases}

Central nervous system diseases are hard to treat due to limited surgical treatment options. The fragile brain tissue and low penetration through the blood-brain barrier result in inadequate treatment and prognosis for many diseases. With the emergence of MSC-EXOs, researchers have discovered that using MSC-EXOs to carry RNA molecules to reach the central nervous 
system is a promising method for treating related diseases [62]. Glioma (GBM) is a malignant tumor with an inferior prognosis in the brain. Studies have shown that the occurrence and development of GBM are closely related to the abnormal activity of individual miRNAs [92]. Wang et al. found that the expression of miR-34a is down-regulated in GBM cells, while the expression of MYCN (a member of the MYC family that encodes a protein with a primary helix-loop-helix domain) is up-regulated. MiR-34a can target and negatively regulate the expression of MYCN. They loaded miR-34a into MSC-EXOs and performed in vivo and in vitro experiments. The results showed that the growth and proliferation of GBM were successfully inhibited, and the chemotherapeutic sensitivity of GBM cells to Temozolomide (TMZ) was improved by silencing MYCN [93]. Glioblastoma is the most common malignant tumor in the adult brain. Due to its strong invasive ability, the survival time of patients is short, and the surgical effect is little [94]. Therefore, by exploring its pathogenesis, it has great potential to use the drug transportability of MSC-EXOs to find its treatment.

$\mathrm{AD}$ is a progressive neurodegenerative disease with insidious onset. The exact cause and effective treatment are still unclear. Studies have found that MiR-29 is down-regulated in $\mathrm{AD}$, which may be related to the pathogenesis of AD [95]. Jahangard et al. loaded MiR29 in MSC-EXOs and delivered it to the hippocampus by local injection. The target genes of MiR-29 are mainly BACE1 ( $\beta$-site amyloid precursor protein cleaving enzyme 1 ) and BIM (Bcl-2 interacting mediator of cell death (BCL2-like11)). The results showed that miR29 was up-regulated, with its main targets down-regulated in hippocampus areas injected with MSC-EXOs. They reduced the pathological effects of amyloid- $\beta(A \beta)$ peptides in a rat model of AD. This study proved that engineered exosomes had a specific protective effect on amyloid pathogenesis and showed a positive correlation in restoring the learning function of the hippocampus. However, there is a lack of data on the biodistribution of MSC-EXOs and the ability of MSC-EXOs to cross the blood-brain barrier successfully. The data are essential for the clinical application of the drug and need to be explored further [96]. In this study, the local injection was used to inject exosomes into the hippocampus. In clinical applications, local injection is highly effective in some cases but is not suitable when the drug has high concentration, strong irritation or large single injection volume. For $\mathrm{AD}$, it is still essential to explore its exact pathogenesis. Once its mechanism is clarified, the related drug delivery methods will positively affect $A D$ treatment.

\section{For spinal cord injury}

Spinal cord injury (SCI) is a severe neurological disease that can cause sensory and motor nerve dysfunction in corresponding spinal cord segments. Due to the poor regeneration function of neurons, there is still a lack of clinically effective treatment methods so far. The development of stem cell transplantation has brought a new direction for the treatment of SCI, but because stem cell transplantation faces many risks, researchers have found that using MSC-EXOs to deliver related RNA can also achieve neuron protection or repair. The researchers loaded miRNA-29b, miR-126, and miR-544 into MSC-EXOs by transfecting MSC $[63,68,97]$. The results show that the above three studies have achieved good results. Exosomes carrying the corresponding RNA promoted angiogenesis and nerve regeneration after spinal cord injury, and spinal cord injury has been significantly improved. The above three studies all achieved drug delivery through intravenous injection, and some researchers creatively used intranasal injection to treat spinal cord injury. Guo et al. loaded phosphatase and tensin homolog small interfering RNA (ExoPTEN) into MSC-EXOs to reduce the expression of PTEN in the area of spinal cord injury. PTEN is expressed in neurons and regenerating axons and can inhibit the growth of axons by down-regulating cytoplasmic mammalian target of rapamycin (mTOR) activity. The results showed that after intranasal administration, MSC-EXOs successfully migrated to the injury site to improve neurological function. It has a better effect on the injury site compared to intravenous injection [98]. So far, the mechanism of using MSC-EXOs to deliver RNA to treat spinal cord injury is still unclear. Further researches need to be conducted to see if there is any other treatment method for different impacts.

In general, the use of MSC-EXOs for the targeted delivery of RNA is effective. MSC-EXOs from different sources contain different kinds of abundant RNA molecules. Researchers adjust the cell activities by changing the level of the corresponding RNA or loading exogenous RNA molecules to treat certain diseases. Both in vivo and in vitro experiments have promising results. However, the current research lacks evidence on whether RNA loading into normal cells will adversely affect it. Researchers need to further explore the operating mechanism of RNA involved in cell activities and improve the MSC-EXOs targeting to reduce the impact on normal cells.

\section{For diabetes and its complications}

Diabetes is a metabolic disease characterized by chronic hyperglycemia. $\beta$-cells play an important role in both type 1 and type 2 diabetes. Therefore, reversing $\beta$ cell 
injury or promoting $\beta$-cells regeneration is crucial in diabetes treatment [99]. Chen et al. explored the effect of miR-21 loaded with MSC-EXOs on the apoptosis and damage of $\beta$-cells caused by hypoxia. The results showed that miR-21 could alleviate endoplasmic reticulum stress and inhibit p38 MAPK signaling to protect $\beta$-cells against apoptosis induced by hypoxia [100]. Wen et al used MSC-EXOs to transport siFas and anti-miR-375 to the islets. The results showed that it could down-regulate Fas and miR-375 levels, suppress $\beta$-cells apoptosis, and improve the viability and function of human islets against inflammatory cytokines [101]. Islet transplantation is the most effective diabetes treatment. $\beta$-cells apoptosis caused by hypoxia and immune rejection after transplantation are the main obstacles to islet transplantation [100, 101]. The above two experiments overcame the above obstacles by MSC-EXOs carrying RNA, providing a new solution for the successful islet transplantation.

Long-term hyperglycemia can potentially lead to microvascular disease and multiple serious tissue and organs complications, such as diabetic nephropathy, diabetic eye disease, and diabetic foot ulcer (DFU) $[99,102]$. Diabetic nephropathy is related to genetic and environmental factors, causing continuous and irreversible damage to the glomeruli and tubulointerstitium of the kidney [103]. Hao et al. transfected miR$125 \mathrm{a}$ mimic into MSC-EXOs. The results indicated that miR-125a carried by MSC-EXOs could bind to histone deacetylase 1, thus down-regulating the endothelin-1 expression and reducing the diabetic nephropathy-like symptoms and renal impairment. Therefore, the development of diabetic nephropathy could be delayed [104]. Diabetic retinopathy is one of the main manifestations of diabetic eye disease. Zhang et al. found that MSCEXOs overexpressing miR-126 could down-regulate the high-mobility group box 1 signaling pathway to inhibit the activation of NF-jB/p65 (a mediator that regulated the expression of inflammatory factors), thus improving hyperglycemia-induced retinal inflammation [105]. Long noncoding RNA (lncRNA) H19 was transfected into MSC-EXOs to explore its role in the healing process of a mouse with DFU. The results showed that the lncRNA H19 in MSC-EXOs could inhibit microRNA152-3p and promote phosphatase and tensin homolog expression, thus regulating the proliferation and migration of fibroblasts and promoting the recovery of DUF. The blocked phosphatidylinositol-4,5-bisphosphate 3-kinase (PI3K)/protein kinase B (Akt) signaling pathway also can promote DUF recovery [106]. Controlling blood sugar levels is essential to treat the complications of diabetes. Diabetes complications are mostly related to the microvascular disease under high glucose levels in the body, but the specific mechanism is still unclear and needs to be further explored [99]. At present, diabetes and its complications still lack effective radical cure methods. MSC-EXOs is expected to become a new carrier to treat diabetes and its complications due to its rich internal regulatory factors and special biological characteristics.

\section{For cardiovascular disorders}

In cardiovascular diseases, MSC-EXOs can be applied to transport RNA to the lesion site, which can regulate angiogenesis, promote heart function recovery, and inhibit myocardial fibrosis. Ma et al. used electroporation to load miR-132 into MSC-EXOs to explore its effect on angiogenesis. The results showed that miR132 in MSC-EXOs targeted RAS p21 protein activator 1 (a negative regulator of blood vessel germination and blood vessel branching) and increased tube formation of endothelial cells in in vitro experiments. In the mouse myocardial infarction model, MSC-EXOs promoted the formation of new blood vessels in the infarcted area and the recovery of heart function [107]. Similarly, Pan et al. delivered miR-126 mimic to endothelial cells through MSC-EXOs, which activated the PI3K/Akt/eNOS pathway, down-regulated cleaved caspase-3 expression, and increased the expression of pro-angiogenic factors, thereby enhancing survival and angiogenesis in endothelial cells damaged by hypoxia/ reoxygenation [108]. According to the above studies, MSC-EXOs can be used as a natural therapeutic delivery vehicle, absorbed by endothelial cells. MSC-EXOs play an important role in preventing endothelial cell damage caused by hypoxia/reoxygenation and promoting angiogenesis and revascularization. In addition to promoting angiogenesis, MSC-EXOs-loaded RNA can inhibit myocardial fibrosis in myocardial infarction. Wang et al. loaded miR-19a/19b into MSC-EXO by transfection and introduced it into the infarcted area, while transplanting MSCs to explore the impact on myocardial infarction. The results showed that the MSC-EXO inhibited the apoptosis of cardiac HL-1 cells and reduced the area of fibrosis of cardiac tissue in a mouse myocardial infarction model. Interestingly, the reduction in myocardial fibrosis did not prevent the scar formation (an important process to maintain the structural integrity of the ventricular wall), but only reduced the harmful effects of myocardial fibrosis [70]. The research creatively transplanted both MSC-EXOs and MSCs into the infarcted area, promoting the recovery of heart function and reducing myocardial fibrosis. This study provided a new "combination" form in the field of cardiac protection, but extensive experiments are needed to verify the biosafety of this strategy. 


\section{For senescence-related disorders}

Aging can cause organ system diseases such as vascular dysfunction and osteoporosis. However, its specific mechanism is unclear yet, and effective prevention methods are not available. Oxidative stress is closely related to the pathogenesis of aging-related diseases, which activates the transforming growth factor- $\beta$ (TGF- $\beta$ ) pathway and subsequently up-regulates senescence markers p21 [109, 110]. Han et al. loaded miR675 into MSC-EXOs by transfection to explore its therapeutic effect on senescence-induced vascular dysfunction. According to the results, miR-675 can inhibit the expression of TGF- $\beta 1$ protein by targeting TGF$\beta 1$ and then down-regulate the TGF- $\beta 1 / \mathrm{pSMAD} / \mathrm{p} 21$ signaling pathway, thereby preventing aging-induced vascular dysfunction. In the study, MSC-EXOs were encapsulated in a hydrogel to improve the stability and half-life of exosomes and the therapeutic effect of exosomes [110]. Angiogenesis is closely related to the formation and regeneration of bones [111]. Lu et al. reported that MSC-EXOs loaded with miR-29a can promote angiogenesis and osteogenesis. They found that miR-29a in old bone marrow mesenchymal stem cells (BMSCs) lines is significantly lower than that in young ones, which may be related to bone loss in old age. MSC-EXOs loaded with miR-29a can promote bone mass increase by promoting blood vessels formation, which may become a potential treatment for senescence-related osteoporosis [112]. The proliferation and differentiation ability of BMSCs also play an important role in bone formation. Jia et al. explored the effect of young MSC-EXOs on old BMSCs, and the results showed that MSC-EXOs enhanced the proliferation and osteogenic ability of BMSCs [113]. However, the experiment did not explain which components in MSC-EXOs work. We can further explore the ingredients that play a role in MSC-EXOs and use engineering technology to increase the content of corresponding components. Then, using MSC-EXOs to transport ingredients can become a new solution for bone diseases in elderly patients. In general, further exploration of the pathogenesis of aging-related diseases is the key.

\section{Delivery of small molecule drugs by MSC-EXOs}

Targeted delivery can improve the efficacy of the drug on the target tissue and reduce the side effects of the drug. Researchers have loaded doxorubicin, paclitaxel, magnolol into MSC-EXOs to achieve targeted treatment of various diseases. Targeted delivery of MSC-EXOs is primarily used in the treatment of tumor. Gomari et al. explored the use of MSC-EXOs to deliver paclitaxel and adriamycin to treat breast cancer. They first compared the delivery efficiency of targeted modified MSC-EXOs loaded with doxorubicin and unmodified MSC-EXOs and free doxorubicin on HER2-positive breast cancer cells. The results showed that the delivery efficiency of targeted modified MSC-EXOs was significantly higher than that of the control group, but this difference gradually decreased as the concentration of MSC-EXOs increased. This result indicates that doxorubicin can be delivered through the targeted modified MSC-EXOs to achieve a higher level of targeted delivery at a lower systemic dose level, reducing its systemic side effects [38]. Then, Gomari et al. demonstrated that doxorubicin delivered by MSC-EXOs could significantly reduce the growth rate of tumors in a mouse breast cancer model [114]. Melzer et al. loaded paclitaxel into MSC-EXOs to explore its anti-tumor effect. The results showed that MSC-EXOs loaded with paclitaxel significantly reduced the tumor volume and inhibited the distant metastasis in the liver, spleen, and kidneys. More importantly, the use of paclitaxel was also significantly reduced [115]. In addition to breast cancer, MSC-EXOs loaded with anti-cancer drugs have also been used to treat other cancers, such as liver cancer, pancreatic cancer, and oral squamous cell carcinoma (Table 3) [116-120]. At present, because most anti-cancer drugs damage normal tissues and have strong side effects, loading drugs into MSC-EXOs for targeted delivery in vivo is mainly used to treat malignant tumors.

Table 3 Delivery of DRUG by MSC-EXOs

\begin{tabular}{|c|c|c|c|c|c|c|}
\hline Aim & Exosomes origin & Loading methods & Administration route & Model & DRUG & References \\
\hline Breast cancers & HucMSC & Incubation & Intravenous injection & Mice & Paclitaxel & {$[115]$} \\
\hline Breast cancers & MSC & Electroporation & In vitro cell experiment & & Doxorubicin & {$[114]$} \\
\hline Hepatocellular carcinoma & BMSC & Electroporation & Intravenous injection & Mice & Norcantharidin (NCTD) & {$[117]$} \\
\hline Osteosarcoma & BMSC & Dialyze & In vitro cell experiment & & Doxorubicin & {$[119]$} \\
\hline Pancreatic cancer & BMSC & Electroporation & Intravenous injection & Mice & $\begin{array}{l}\text { Gemcitabine } \\
\text { monophosphate(GEMP) }\end{array}$ & {$[120]$} \\
\hline Oral squamous cell carcinoma & MSC & Incubation & Injected subcutaneously & Mice & Cabazitaxel (CTX) & {$[116]$} \\
\hline Several cancer cell lines & MSC & Sonication & In vitro cell experiment & & Honokiol & [118] \\
\hline
\end{tabular}


Loading small molecule drugs into MSC-EXOs to treat inflammation, tissue regeneration, and other treatments is also very promising. Current research results show that small molecule anticancer drugs can be successfully loaded into MSC-EXOs to deliver to the target site with higher efficiency, maintaining a good drug release curve. The homing performance and specific ligands connection of MSC-EXOs also improved its targeting ability. However, the mechanism of the tumor is complicated. Some types of exosomes can even promote tumor proliferation. Therefore, it is necessary to choose a suitable source for MSC-EXOs to load with, and more researches need to be conducted on the relationship between exosomes and different tumors.

\section{Delivery of protein by MSC-EXOs}

Protein is the primary component of life structure, and it plays an essential role in various life activities in the body. Researchers have loaded growth regulators, tumor necrosis factors, enzymes, and other proteins into MSCEXOs. Explore the targeted delivery potential of MSCEXOs-loaded proteins. It is mainly used in the treatment of brain injury, cardiovascular disorders, tumor, etc. Huang et al. increased the content of PEDF in adiposederived MSCs (ADSCs) by overexpression to identify its protective effect on brain injury through in vitro cell experiments and in vivo experiments. The results showed that MSC-EXOs modified by PEDF successfully ameliorated the cerebral ischemia-reperfusion injury by regulating cell autophagy and apoptosis. However, this study did not explore the penetration of the blood-brain barrier and the distribution of MSC-EXOs carrying PEDF in vivo [42]. MA et al. overexpressed Akt into the human umbilical cord (hucMSCs) to study how it works in myocardial infarction. The results show that it accelerates the endothelial cell proliferation and migration and blood vessels formation in vitro and significantly improves heart function in vivo experiments. The researchers pointed out that this may be related to the up-regulation of platelet-derived growth factor D (PDGF-D) expression by AKT-MSC-EXOs [121]. Liu et al. delivered angiopoietin-2 (Ang-2) to human umbilical vein endothelial cells (HUVECs) through MSC-EXOs, which enhanced the proliferation, migratory, and tube-forming ability of HUVECs [122]. Zhuang et al. used genetic engineering methods to anchor cell-penetrating peptides (CPPs) and tumor necrosis factor (TNF- $\alpha$ ) on the surface of MSCEXOs. SPIONs are connected to the surface through chemical reactions. The results showed that CTNF- $\alpha$ exosome-SPIONs obtained better anti-tumor properties and reduced the side effects in vivo. The research creatively anchored the "cargo" on the surface of exosomes instead of inside them, providing a new idea for the targeted transportation of proteins in the future [123].

At present, the primary method of loading protein into MSC-EXOs is to overexpress the protein. Whether this method of adjusting the protein content will affect other functions of the cell is temporarily unknown. Studies have also pointed out that exosomes are most likely to act through protein rather than RNA [124]. Therefore, further exploring the mechanism of RNA and protein in exosomes is necessary. Other studies also confirmed that MSC-EXOs are feasible as a protein transport carrier [122, 125-128] (Table 4).

\section{Conclusions and perspectives}

According to recent studies, both advantages and challenges are identified in the area of MSC-EXOs delivery. The summary below includes the advantages and challenges of MSC-EXOs as drug delivery system:

Advantages: (1) Many studies have shown that the biological function of MSCs is achieved by paracrine EV. MSC-EXOs perfectly inherit the advantages of low immunogenicity and solved many problems in drug delivery. (2) MSC-EXOs contain a wide variety of proteins, RNA, and other molecules. Increasing or reducing the content of a specific molecule can easily reach the regulation of a specific disease pathway. (3) The surface

Table 4 Delivery of protein by MSC-EXOs

\begin{tabular}{lllllll}
\hline Aim & Exosomes origin & Loading methods & Administration route & Model & Protein & References \\
\hline $\begin{array}{l}\text { Ameliorate cerebral ischemia- } \\
\text { reperfusion injury }\end{array}$ & ADSCS & Overexpression & Local injection & Mice & PEDF & [42] \\
Improve cardiac regeneration & HucMSCS & Transfection & Intravenous injection & Mice & Akt & [121] \\
Anti-tumor & MSC & Electroporation & In vitro cell experiment & N/A & TNF-a & {$[123]$} \\
Anti-tumor & BMSCs & Transfection & Intravenous injection & Mice & TRAILC1] & {$[126]$} \\
Cystic fibrosis & BMSCS & Transfection & In vitro cell experiment & N/A & Zinc Finger Protein & {$[128]$} \\
Prevent cisplatin injury & HucMSC & Transfection & In vitro cell experiment & N/A & 14-3-3protein & {$[125,127]$} \\
Enhance angiogenesis & HucMSCS & Overexpression & Subcutaneous injection & Mice & Angiopoietin-2 & [122] \\
\hline
\end{tabular}

N/A, not applicable. (1)TRAIL, tumor necrosis factor-related apoptosis-inducing ligand 
and interior of MSC-EXOs can be modified, and various targeting molecules can be attached to its surface to improve MSC-EXOs targeting, which has robust expandability.

Challenges: (1) At present, researchers have proposed a variety of optimization methods for MSC-EXOs production and purification, but most methods lack standardization and quality control. The contents and functions of MSC-EXOs are different. Before the standardized production of MSC-EXOs, the accurate judgment and selection of MSC-EXOs are necessary. Integrating standardized, convenient, and strictly controlled production and purification methods is a promising solution. (2) The improvement in MSC-EXOs targeting is highly dependent on its targeted modification, which requires a better understanding of the mechanism of disease occurrence and development. For unclear pathogenesis such as Parkinson's and Alzheimer's, it is necessary to find more efficient and accurate targeting molecules or methods by exploring its pathogenesis to improve drug delivery targeting. (3) The biodistribution and half-life of MSCEXOs in the human body need to be further clarified. The main routes of administration of MSC-EXOs are intravenous injection, local injection, intranasal administration, etc. The different routes of administration will affect the biodistribution of the drug in the body, which requires further comparison and exploration by researchers. The detection of the biodistribution of MSC-EXOs in vivo is closely related to the in vivo labeling of MSC-EXOs. Researchers can combine imaging and other methods with the labeling technology of MSC-EXOs to explore its biodistribution in the body. (4) Current disease models are mostly mice or in vitro cell experiments used for cancer and other disease studies, which are relatively simple and lack data for comparative research with other disease models.

Accurate drug delivery in the human body can improve drug efficacy and reduce side effects. MSC-EXOs, as one of the most potential in vivo transport carriers, need to be further studied and developed by researchers.

\footnotetext{
Abbreviations

MSC-EXOs: The exosomes secreted by mesenchymal stem cells; MSCs: Mesenchymal stem cells; BG: 4555 Bioglass ${ }^{\circledR}$; nSMase2: Neutral sphingomyelinase-2; TFF: Tangential flow filtration; UC: Ultracentrifugation; SC: Sucrose cushion; CR: Commercial reagent; GMP: Good Manufacture Practice of Medical Products; HucMSC: Human umbilical cord MSC; AMSC: Adipose tissue-derived MSC; IMTP: Ischemic myocardium-targeting peptide; RVG: Rabies viral glycoprotein; SPIONs: Superparamagnetic iron oxide nanoparticles; Cur: Curcumin; IOPN: Iron oxide nanoparticles; FDA: Food and Drug Administration; GNPs: Gold nanoparticles; PDAC: Pancreatic ductal adenocarcinoma; LNA: Locked nucleic acid; miR-122: MicroRNA-122; GBM: Glioma; MYCN: A member of the MYC family that encodes a protein with a primary helix-loop-helix domain; TMZ: Temozolomide; AD: Alzheimer's disease; SCI: Spinal cord injury; PEDF: Pigment epithelium-derived factor; ADSCs: Adipose-derived MSCs; Akt: Protein kinase B; PDGF-D: Platelet-derived growth factor D; CPPs: Cell-penetrating peptides;
}

TNF-a: Tumor necrosis factor; A $\beta$ : Amyloid- $\beta$; IncRNA: Long noncoding RNA; DFU: Diabetic foot ulcer; Ang-2: Angiopoietin-2; HUVECs: Human umbilical vein endothelial cells; PI3K: Bisphosphate 3-kinase; TGF- $\beta$ : Transforming growth factor- $\beta$; BMSCs: Bone marrow mesenchymal stem cells.

\section{Acknowledgements}

Not applicable

\section{Authors' contributions}

SY, LGL, and ZK drafted the review; LGL and LJN revised the study; CQ generated the graphs; LJN guided the construction of the manuscript; LTJ edited the review; LJN provided input on the scope and content of the review. All authors have read and approved the manuscript.

\section{Funding}

This study was supported by grants from the Science and Technology Development Project of Jilin Province (\#3D5197434429), the Youth Program of the National Natural Science Foundation of China (\#3A4205367429), and the Education Project of Jilin University (\#419070600046).

\section{Availability of data and materials}

All data generated or analyzed during this study are included in this published article.

\section{Declarations}

Ethics approval and consent to participate.

Not applicable.

\section{Consent for publication.}

Not applicable.

\section{Competing interests}

The authors declare that they have no competing interests.

\section{Author details}

${ }^{1}$ Department of General Surgery, The Second Hospital of Jilin University, No. 218 Ziqiang Street, Changchun 130041, China. ${ }^{2}$ Operating Theater and Department of Anestheology, The Second Hospital of Jilin University, Changchun 130041, China. ${ }^{3}$ Department of Education, The Second Hospital of Jilin University, Changchun 130041, China.

Received: 4 August 2021 Accepted: 16 October 2021

Published online: 30 October 2021

\section{References}

1. Keshtkar S, Azarpira N, Ghahremani MH. Mesenchymal stem cellderived extracellular vesicles: novel frontiers in regenerative medicine. Stem Cell Res Ther. 2018;9(1):63.

2. Chen YS, et al. Exosomes in clinical trial and their production in compliance with good manufacturing practice. Ci Ji Yi Xue Za Zhi. 2020;32(2):113-20

3. Wang M, Yuan Q, Xie L. Mesenchymal stem cell-based immunomodulation: properties and clinical application. Stem Cells Int. 2018;2018:3057624.

4. Su Y, et al., Current advances and challenges of mesenchymal stem cells-based drug delivery system and their improvements. Int J Pharm, 2021.600: p. 120477.

5. Tang Y, Zhou Y, Li HJ. Advances in mesenchymal stem cell exosomes: a review. Stem Cell Res Ther. 2021;12(1):71.

6. Li M, et al., exosomes from different cells: characteristics, modifications, and therapeutic applications. eur J Med Chem, 2020. 207: p. 112784.

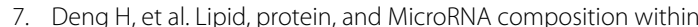
mesenchymal stem cell-derived exosomes. Cell Reprogram. 2018;20(3):178-86. 
8. Cai J, et al. Extracellular vesicles derived from different sources of mesenchymal stem cells: therapeutic effects and translational potential. Cell Biosci. 2020;10:69.

9. Lai RC, et al. Exosomes for drug delivery - a novel application for the mesenchymal stem cell. Biotechnol Adv. 2013;31(5):543-51.

10. Zhang $M$, et al. Exosome-based nanocarriers as bio-inspired and versatile vehicles for drug delivery: recent advances and challenges. J Mater Chem B. 2019;7(15):2421-33.

11. Phan J, et al. Engineering mesenchymal stem cells to improve their exosome efficacy and yield for cell-free therapy. J Extracell Vesicles. 2018;7(1):1522236.

12. Lai RC, et al. Isolation and characterization of exosome from human embryonic stem cell-derived c-Myc-immortalized mesenchymal stem cells. Methods Mol Biol. 2016;1416:477-94.

13. Chen TS, et al. Enabling a robust scalable manufacturing process for therapeutic exosomes through oncogenic immortalization of human ESC-derived MSCs. J Transl Med. 2011;9:47.

14. Wang J, et al., Boosting the biogenesis and secretion of mesenchymal stem cell-derived exosomes. Cells, 2020;9(3).

15. Patel DB, et al. Towards rationally designed biomanufacturing of therapeutic extracellular vesicles: impact of the bioproduction microenvironment. Biotechnol Adv. 2018;36(8):2051-9.

16. Cao J, et al. Three-dimensional culture of MSCs produces exosomes with improved yield and enhanced therapeutic efficacy for cisplatininduced acute kidney injury. Stem Cell Res Ther. 2020;11(1):206.

17. Sung DK, et al., Thrombin preconditioning of extracellular vesicles derived from mesenchymal stem cells accelerates cutaneous wound healing by boosting their biogenesis and enriching cargo content. J Clin Med, 2019;8(4)

18. Luo Z, et al. Hypoxia preconditioning promotes bone marrow mesenchymal stem cells survival by inducing HIF-1a in injured neuronal cells derived exosomes culture system. Cell Death Dis. 2019;10(2):134.

19. Wu Z, He D, Li H. Bioglass enhances the production of exosomes and improves their capability of promoting vascularization. Bioact Mater. 2021;6(3):823-35.

20. Haraszti RA, et al. Exosomes produced from 3D cultures of MSCs by tangential flow filtration show higher yield and improved activity. Mol Ther. 2018;26(12):2838-47.

21. Bari E, et al. Freeze-dried and GMP-compliant pharmaceuticals containing exosomes for acellular mesenchymal stromal cell immunomodulant therapy. Nanomedicine (Lond). 2019;14(6):753-65.

22. Gorgun C, et al., Isolation and flow cytometry characterization of extracellular-vesicle subpopulations derived from human mesenchymal stromal cells. Curr Protoc Stem Cell Biol, 2019;48(1): p. e76.

23. Nordin JZ, et al. Tangential flow filtration with or without subsequent bind-elute size exclusion chromatography for purification of extracellular vesicles. Methods Mol Biol. 2019;1953:287-99.

24. Börger $V$, et al., Scaled isolation of mesenchymal stem/stromal cellderived extracellular vesicles. Curr Protoc Stem Cell Biol, 2020;55(1): p. e128.

25. Nordin JZ, et al. Ultrafiltration with size-exclusion liquid chromatography for high yield isolation of extracellular vesicles preserving intact biophysical and functional properties. Nanomedicine. 2015;11(4):879-83.

26. Ludwig AK, et al. Precipitation with polyethylene glycol followed by washing and pelleting by ultracentrifugation enriches extracellular vesicles from tissue culture supernatants in small and large scales. J Extracell Vesicles. 2018;7(1):1528109.

27. Lässer C, Jang SC, Lötvall J. Subpopulations of extracellular vesicles and their therapeutic potential. Mol Aspects Med. 2018;60:1-14.

28. Chopra N, et al. Biophysical characterization and drug delivery potential of exosomes from human Wharton's jelly-derived mesenchymal stem cells. ACS Omega. 2019;4(8):13143-52.

29. Watson DC, et al. Scalable, cGMP-compatible purification of extracellular vesicles carrying bioactive human heterodimeric IL-15/lactadherin complexes. J Extracell Vesicles. 2018;7(1):1442088.

30. Roura S, Bayes-Genis A, Toward standardization of mesenchymal stromal cell-derived extracellular vesicles for therapeutic use: a call for action. Proteomics, 2019;19(1-2): p. e1800397.

31. Sun $L$, et al. Safety evaluation of exosomes derived from human umbilical cord mesenchymal stromal cell. Cytotherapy. 2016;18(3):413-22.
32. Rohde E, Pachler K, Gimona M. Manufacturing and characterization of extracellular vesicles from umbilical cord-derived mesenchymal stromal cells for clinical testing. Cytotherapy. 2019;21(6):581-92.

33. Xu M, et al., Recent advancements in the loading and modification of therapeutic exosomes. Front Bioeng Biotechnol, 2020;8:586130.

34. Lou G, et al. Exosomes derived from miR-122-modified adipose tissuederived MSCs increase chemosensitivity of hepatocellular carcinoma. J Hematol Oncol. 2015;8:122.

35. Zhang D, et al. Enrichment of selective miRNAs in exosomes and delivery of exosomal miRNAs in vitro and in vivo. Am J Physiol Lung Cell Mol Physiol. 2017;312(1):L110-I121.

36. Lamichhane TN, Raiker RS, Jay SM. Exogenous DNA loading into extracellular vesicles via electroporation is size-dependent and enables limited gene delivery. Mol Pharm. 2015;12(10):3650-7.

37. Familtseva A, Jeremic N, Tyagi SC. Exosomes: cell-created drug delivery systems. Mol Cell Biochem. 2019;459(1-2):1-6.

38. Gomari $\mathrm{H}$, et al. Targeted delivery of doxorubicin to HER2 positive tumor models. Int J Nanomedicine. 2019;14:5679-90.

39. Jeyaram A, et al. Enhanced loading of functional miRNA Cargo via $\mathrm{pH}$ gradient modification of extracellular vesicles. Mol Ther. 2020;28(3):975-85.

40. Kooijmans SAA, et al. Electroporation-induced siRNA precipitation obscures the efficiency of siRNA loading into extracellular vesicles. J Control Release. 2013;172(1):229-38.

41. Hood JL, Scott MJ, Wickline SA. Maximizing exosome colloidal stability following electroporation. Anal Biochem. 2014;448:41-9.

42. Huang $X$, et al. Exosomes derived from PEDF modified adipose-derived mesenchymal stem cells ameliorate cerebral ischemia-reperfusion injury by regulation of autophagy and apoptosis. Exp Cell Res. 2018;371(1):269-77.

43. György B, et al. Therapeutic applications of extracellular vesicles: clinical promise and open questions. Annu Rev Pharmacol Toxicol. 2015;55:439-64.

44. David A. Peptide ligand-modified nanomedicines for targeting cells at the tumor microenvironment. Adv Drug Deliv Rev. 2017;119:120-42.

45. Wang Y, et al. Rapid delivery of Hsa-miR-590-3p using targeted exosomes to treat acute myocardial infarction through regulation of the cell cycle. J Biomed Nanotechnol. 2018;14(5):968-77.

46. Wang $X$, et al., Engineered exosomes with ischemic myocardiumtargeting peptide for targeted therapy in myocardial infarction. J Am Heart Assoc, 2018;7(15):e008737.

47. Lai $C P$, et al. Dynamic biodistribution of extracellular vesicles in vivo using a multimodal imaging reporter. ACS Nano. 2014;8(1):483-94.

48. Cui GH, et al. RVG-modified exosomes derived from mesenchymal stem cells rescue memory deficits by regulating inflammatory responses in a mouse model of Alzheimer's disease. Immun Ageing. 2019;16:10.

49. Jia G, et al. NRP-1 targeted and cargo-loaded exosomes facilitate simultaneous imaging and therapy of glioma in vitro and in vivo. Biomaterials. 2018;178:302-16

50. Tian T, et al. Surface functionalized exosomes as targeted drug delivery vehicles for cerebral ischemia therapy. Biomaterials. 2018;150:137-49.

51. Salunkhe S, et al. Surface functionalization of exosomes for target-specific delivery and in vivo imaging \& tracking: Strategies and significance. J Control Release. 2020;326:599-614.

52. Kim HY, et al., Mesenchymal stem cell-derived magnetic extracellular nanovesicles for targeting and treatment of ischemic stroke. Biomaterials, 2020;243:119942.

53. Kim HY, et al. Therapeutic efficacy-potentiated and diseased organtargeting nanovesicles derived from mesenchymal stem cells for spinal cord injury treatment. Nano Lett. 2018;18(8):4965-75.

54. Lee JR, et al., Nanovesicles derived from iron oxide nanoparticlesincorporated mesenchymal stem cells for cardiac repair. Sci Adv, 2020;6(18):eaaz0952.

55. Di Rocco G, Baldari S, Toietta G. Towards therapeutic delivery of extracellular vesicles: strategies for in vivo tracking and biodistribution analysis. Stem Cells Int. 2016;2016:5029619.

56. Cohen O, et al., Golden' exosomes as delivery vehicles to target tumors and overcome intratumoral barriers: in vivo tracking in a model for head and neck cancer. Biomater Sci, 2021.

57. Hwang DW, et al. Noninvasive imaging of radiolabeled exosomemimetic nanovesicle using (99m)Tc-HMPAO. Sci Rep. 2015:5:15636. 
58. Xu R, et al. In vivo monitoring and assessment of exogenous mesenchymal stem cell-derived exosomes in mice with ischemic stroke by molecular imaging. Int J Nanomedicine. 2020;15:9011-23.

59. Perets N, et al. Golden Exosomes Selectively Target Brain Pathologies In Neurodegenerative And Neurodevelopmental Disorders. Nano Lett. 2019;19(6):3422-31.

60. Betzer $\mathrm{O}$, et al. In vivo neuroimaging of exosomes using gold nanoparticles. ACS Nano. 2017;11(11):10883-93.

61. Dragomir MP, Knutsen E, Calin GA. SnapShot: Unconventional miRNA Functions. Cell. 2018;174(4):1038-1038.e1.

62. Kim R, et al. Exosomes derived from microRNA-584 transfected mesenchymal stem cells: novel alternative therapeutic vehicles for cancer therapy. BMB Rep. 2018;51(8):406-11.

63. Yu T, et al., Exosomes secreted from miRNA-29b-modified mesenchymal stem cells repaired spinal cord injury in rats. Braz J Med Biol Res, 2019;52(12): p. e8735.

64. Shen $\mathrm{H}$, et al. Role of exosomes derived from miR-133b modified MSCs in an experimental rat model of intracerebral hemorrhage. J Mol Neurosci. 2018;64(3):421-30.

65. Xin H, et al., MiR-17-92 enriched exosomes derived from multipotent mesenchymal stromal cells enhance axon-myelin remodeling and motor electrophysiological recovery after stroke. J Cereb Blood Flow Metab, 2020:271678×20950489.

66. Lou G, et al. MiR-199a-modified exosomes from adipose tissuederived mesenchymal stem cells improve hepatocellular carcinoma chemosensitivity through mTOR pathway. J Exp Clin Cancer Res. 2020;39(1):4.

67. Qu Y, et al. Exosomes derived from miR-181-5p-modified adiposederived mesenchymal stem cells prevent liver fibrosis via autophagy activation. J Cell Mol Med. 2017;21(10):2491-502.

68. Huang $\mathrm{JH}$, et al. Exosomes derived from miR-126-modified MSCs promote angiogenesis and neurogenesis and attenuate apoptosis after spinal cord injury in rats. Neuroscience. 2020;424:133-45.

69. Xu HK, et al. Multifunctional role of microRNAs in mesenchymal stem cell-derived exosomes in treatment of diseases. World J Stem Cells. 2020;12(11):1276-94.

70. Wang S, et al. miR-19a/19b-loaded exosomes in combination with mesenchymal stem cell transplantation in a preclinical model of myocardial infarction. Regen Med. 2020;15(6):1749-59.

71. Xu Y, et al. Anticancer effects of miR-124 delivered by BM-MSC derived exosomes on cell proliferation, epithelial mesenchymal transition, and chemotherapy sensitivity of pancreatic cancer cells. Aging (Albany NY). 2020;12(19):19660-76.

72. O'Brien KP, et al. Employing mesenchymal stem cells to support tumor-targeted delivery of extracellular vesicle (EV)-encapsulated microRNA-379. Oncogene. 2018:37(16):2137-49.

73. Sharif S, Ghahremani MH, Soleimani M. Delivery of exogenous miR124 to glioblastoma multiform cells by wharton's jelly mesenchyma stem cells decreases cell proliferation and migration, and confers chemosensitivity. Stem Cell Rev Rep. 2018;14(2):236-46.

74. Sun B, et al. miR-644-5p carried by bone mesenchymal stem cell-derived exosomes targets regulation of p53 to inhibit ovarian granulosa cell apoptosis. Stem Cell Res Ther. 2019;10(1):360.

75. Fang $\mathrm{S}$, et al. Osteogenic effect of tsRNA-10277-loaded exosome derived from bone mesenchymal stem cells on steroidinduced osteonecrosis of the femoral head. Drug Des Devel Ther. 2020;14:4579-91.

76. Jing $L$, et al. Exosomal miR-499a-5p inhibits endometrial cancer growth and metastasis via targeting VAV3. Cancer Manag Res. 2020;12:13541-52.

77. Qu Q, et al. miRNA-126-3p carried by human umbilical cord mesenchymal stem cell enhances endothelial function through exosomemediated mechanisms in vitro and attenuates vein graft neointimal formation in vivo. Stem Cell Res Ther. 2020;11(1):464.

78. Wang G, et al., HucMSC-exosomes carrying miR-326 inhibit neddylation to relieve inflammatory bowel disease in mice. Clin Transl Med, 2020;10(2):e113.

79. Sharif S, Ghahremani MH, Soleimani M. Differentiation induction and proliferation inhibition by a cell-free approach for delivery of exogenous miRNAs to neuroblastoma cells using mesenchymal stem cells. Cell J. 2021:22(4):556-64.
80. Shi J, et al. Gene-modified exosomes protect the brain against prolonged deep hypothermic circulatory arrest. Ann Thorac Surg. 2021:111(2):576-85.

81. Shojaei S, et al., Delivery of miR-381-3p Mimic by mesenchymal stem cell-derived exosomes inhibits triple negative breast cancer aggressiveness; an in vitro study. Stem Cell Rev Rep, 2021.

82. Vakhshiteh, F., et al., Exosomes derived from miR-34a-overexpressing mesenchymal stem cells inhibit in vitro tumor growth: a new approach for drug delivery. Life Sci, 2021;266: 118871.

83. Wang R, Xu B, TGF- $\beta 1$-modified MSC-derived exosomal miR-135b attenuates cartilage injury via promoting M2 synovial macrophage polarization by targeting MAPK6. Cell Tissue Res, 2021.

84. Wang Z, et al. Exosomes derived from miR-155-5p-overexpressing synovial mesenchymal stem cells prevent osteoarthritis via enhancing proliferation and migration, attenuating apoptosis, and modulating extracellular matrix secretion in chondrocytes. Cell Biol Toxicol. 2021;37(1):85-96.

85. Zhang $\mathrm{L}$, et al. Exosomes from microRNA-126 overexpressing mesenchymal stem cells promote angiogenesis by targeting the PIK3R2-mediated PI3K/Akt signalling pathway. J Cell Mol Med. 2021;25(4):2148-62.

86. Wang B, et al. Mesenchymal stem cells deliver exogenous microRNA-let7c via exosomes to attenuate renal fibrosis. Mol Ther. 2016;24(7):1290-301.

87. Isobe T, et al., miR-142 regulates the tumorigenicity of human breast cancer stem cells through the canonical WNT signaling pathway. Elife, 2014;3.

88. Naseri Z, et al. Exosome-mediated delivery of functionally active miRNA-142-3p inhibitor reduces tumorigenicity of breast cancer in vitro and in vivo. Int J Nanomedicine. 2018;13:7727-47.

89. Naseri Z, et al. Delivery of LNA-antimiR-142-3p by mesenchymal stem cells-derived exosomes to breast cancer stem cells reduces tumorigenicity. Stem Cell Rev Rep. 2020;16(3):541-56.

90. Xu Y, et al. MicroRNA-122 sensitizes HCC cancer cells to adriamycin and vincristine through modulating expression of MDR and inducing cell cycle arrest. Cancer Lett. 2011;310(2):160-9.

91. Ding $Y$, et al. Exosomes derived from human umbilical cord mesenchymal stromal cells deliver exogenous miR-145-5p to inhibit pancreatic ductal adenocarcinoma progression. Cancer Lett. 2019;442:351-61.

92. Sumazin P, et al. An extensive microRNA-mediated network of RNA-RNA interactions regulates established oncogenic pathways in glioblastoma. Cell. 2011;147(2):370-81.

93. Wang $B$, et al. Human bone marrow-derived mesenchymal stem cell-secreted exosomes overexpressing microRNA-34a ameliorate glioblastoma development via down-regulating MYCN. Cell Oncol (Dordr). 2019;42(6):783-99.

94. Vassallo I, et al. WIF1 re-expression in glioblastoma inhibits migration through attenuation of non-canonical WNT signaling by downregulating the IncRNA MALAT1. Oncogene. 2016;35(1):12-21.

95. Shioya $\mathrm{M}$, et al. Aberrant microRNA expression in the brains of neurodegenerative diseases: miR-29a decreased in Alzheimer disease brains targets neurone navigator 3. Neuropathol Appl Neurobiol. 2010;36(4):320-30.

96. Jahangard $Y$, et al. Therapeutic effects of transplanted exosomes containing miR-29b to a rat model of Alzheimer's Disease. Front Neurosci. 2020:14:564

97. Li C, et al. Exosomes derived from miR-544-modified mesenchymal stem cells promote recovery after spinal cord injury. Arch Physiol Biochem. 2020;126(4):369-75.

98. Guo S, et al. Intranasal delivery of mesenchymal stem cell derived exosomes loaded with phosphatase and tensin homolog sirna repairs complete spinal cord injury. ACS Nano. 2019;13(9):10015-28.

99. Cui $X$, et al. Mesenchymal stem cell-derived exosomes: a promising vec tor in treatment for diabetes and its microvascular complications. Am J Transl Res. 2021;13(5):3942-53.

100. Chen J, et al. Mesenchymal stem cell-derived exosomes protect beta cells against hypoxia-induced apoptosis via miR-21 by alleviating ER stress and inhibiting p38 MAPK phosphorylation. Stem Cell Res Ther. 2020;11(1):97.

101. Wen D, et al. Mesenchymal stem cell and derived exosome as small RNA carrier and Immunomodulator to improve islet transplantation. J Control Release. 2016:238:166-75. 
102. Xiong, J., et al., Mesenchymal Stem Cell Exosomes as a New Strategy for the Treatment of Diabetes Complications. Front Endocrinol (Lausanne), 2021;12:646233.

103. Geng XD, et al. Identification of key genes and pathways in diabetic nephropathy by bioinformatics analysis. J Diabetes Investig. 2019;10(4):972-84.

104. Hao Y, et al. Mesenchymal stem cell-derived exosomes carry MicroRNA125 a to protect against diabetic nephropathy by targeting histone deacetylase 1 and downregulating endothelin-1. Diabetes Metab Syndr Obes. 2021;14:1405-18.

105. Zhang W, Wang Y, Kong Y. Exosomes derived from mesenchymal stem cells modulate miR-126 to ameliorate hyperglycemia-induced retinal inflammation via targeting HMGB1. Invest Ophthalmol Vis Sci. 2019;60(1):294-303.

106. Li B, et al. The MSC-derived exosomal IncRNA H19 promotes wound healing in diabetic foot ulcers by upregulating PTEN via MicroRNA152-3p. Mol Ther Nucleic Acids. 2020;19:814-26.

107. Ma T, et al. MicroRNA-132, delivered by mesenchymal stem cell-derived exosomes, promote angiogenesis in myocardial infarction. Stem Cells Int. 2018:2018:3290372.

108. Pan Q, et al. Exosomes derived from mesenchymal stem cells ameliorate hypoxia/reoxygenation-injured ECs via transferring MicroRNA-126. Stem Cells Int. 2019;2019:2831756.

109. Dai DF, et al. Cardiac aging: from molecular mechanisms to significance in human health and disease. Antioxid Redox Signal. 2012;16(12):1492-526.

110. Han C, et al. Delivery of miR- 675 by stem cell-derived exosomes encapsulated in silk fibroin hydrogel prevents aging-induced vascular dysfunction in mouse hindlimb. Mater Sci Eng C Mater Biol Appl. 2019;99:322-32

111. Kusumbe AP, Ramasamy SK, Adams RH. Coupling of angiogenesis and osteogenesis by a specific vessel subtype in bone. Nature. 2014;507(7492):323-8.

112. Lu GD, et al., BMSC-derived exosomal miR-29a promotes angiogenesis and osteogenesis. Front Cell Dev Biol, 2020;8:608521.

113. Jia Y, et al. Exosomes secreted by young mesenchymal stem cells promote new bone formation during distraction osteogenesis in older rats. Calcif Tissue Int. 2020;106(5):509-17.

114. Gomari H, Forouzandeh M, Soleimani M, Targeted cancer therapy using engineered exosome as a natural drug delivery vehicle. Onco Targets Ther, 2018;11:5753-5762.

115. Melzer C, et al., Taxol-loaded MSC-derived exosomes provide a therapeutic vehicle to target metastatic breast cancer and other carcinoma cells. Cancers (Basel), 2019;11(6).
116. Qiu Y, et al. Antitumor activity of cabazitaxel and MSC-TRAIL derived extracellular vesicles in drug-resistant oral squamous cell carcinoma. Cancer Manag Res. 2020;12:10809-20.

117. Liang L, et al., Treatment for hepatocellular carcinoma is enhanced when norcantharidin is encapsulated in exosomes derived from bone marrow mesenchymal stem cells. Mol Pharm, 2021.

118. Kanchanapally $R$, et al. Exosomal formulation escalates cellular uptake of honokiol leading to the enhancement of its antitumor efficacy. ACS Omega. 2020;5(36):23299-307.

119. Wei $\mathrm{H}$, et al. A nanodrug consisting of doxorubicin and exosome derived from mesenchymal stem cells for osteosarcoma treatment in vitro. Int J Nanomedicine. 2019;14:8603-10.

120. Zhou Y, et al. Bone marrow mesenchymal stem cells-derived exosomes for penetrating and targeted chemotherapy of pancreatic cancer. Acta Pharm Sin B. 2020;10(8):1563-75.

121. Ma J, et al. Exosomes derived from akt-modified human umbilical cord mesenchymal stem cells improve cardiac regeneration and promote angiogenesis via activating platelet-derived growth factor D. Stem Cells Transl Med. 2017;6(1):51-9.

122. Liu J, et al., Exosomes derived from human umbilical cord mesenchymal stem cells accelerate cutaneous wound healing by enhancing angiogenesis through delivering Angiopoietin-2. Stem Cell Rev Rep, 2020.

123. Zhuang M, et al. SPION decorated exosome delivery of TNF-a to cancer cell membranes through magnetism. Nanoscale. 2020;12(1):173-88.

124. Toh WS, et al. MSC exosome works through a protein-based mechanism of action. Biochem Soc Trans. 2018;46(4):843-53.

125. Jia H, et al. HucMSC exosomes-delivered 14-3-3 , enhanced autophagy via modulation of ATG16L in preventing cisplatin-induced acute kidney injury. Am J Transl Res. 2018;10(1):101-13.

126. Shamili FH, et al. Exosomes derived from TRAlL-engineered mesenchymal stem cells with effective anti-tumor activity in a mouse melanoma model. Int J Pharm. 2018;549(1-2):218-29.

127. Wang J, et al. HucMSC exosome-transported 14-3-3 $\zeta$ prevents the injury of cisplatin to HK-2 cells by inducing autophagy in vitro. Cytotherapy. 2018;20(1):29-44

128. Villamizar O, et al., Mesenchymal Stem Cell exosome delivered Zinc Finger Protein activation of cystic fibrosis transmembrane conductance regulator. J Extracell Vesicles, 2021;10(3):e12053.

\section{Publisher's Note}

Springer Nature remains neutral with regard to jurisdictional claims in published maps and institutional affiliations.
Ready to submit your research? Choose BMC and benefit from:

- fast, convenient online submission

- thorough peer review by experienced researchers in your field

- rapid publication on acceptance

- support for research data, including large and complex data types

- gold Open Access which fosters wider collaboration and increased citations

- maximum visibility for your research: over $100 \mathrm{M}$ website views per year

At BMC, research is always in progress.

Learn more biomedcentral.com/submissions 